\title{
Mitral mechanical replacement in young rheumatic women: Analysis of long-term survival, valve-related complications, and pregnancy outcomes over a 3707-patient-year follow-up
}

Figures E1 to E3 are available online. $\mathcal{B}$
From the Department of Cardio-Thoracic and Respiratory Sciences, Second University of Naples, V. Monaldi Hospital, Naples, Italy, ${ }^{\text {a }}$ Department of Cardiovascular Surgery and Transplantation, V. Monaldi Hospital, Naples, Italy, ${ }^{\mathrm{b}}$ and $\mathrm{PhD}$ Program in "Medical-Surgical Physiopathology of the Cardio-Respiratory System and Associated Biotechnologies," Second University of Naples, Naples, Italy. ${ }^{c}$

Received for publication May 24, 2004; revisions received Nov 25, 2004; accepted for publication Nov 30, 2004.

Address for reprints: Luca Salvatore De Santo, MD, Department of Cardio-Thoracic and Respiratory Sciences, Second University of Naples, V. Monaldi Hospital, Via L. Bianchi, 80131 Naples, Italy (E-mail: lucas.desanto@unina2.it).

J Thorac Cardiovasc Surg 2005;130:13-9

$0022-5223 / \$ 30.00$

Copyright (C) 2005 by The American Association for Thoracic Surgery

doi:10.1016/j.jtcvs.2004.11.032
Objective: A follow-up study was performed to assess long-term survival, valverelated complications, and pregnancy outcomes in young rheumatic women undergoing isolated mitral mechanical replacement. The influence of prosthetic type on outcomes was also investigated.

Methods: Between 1975 and 2003, 267 isolated mitral mechanical prostheses were implanted. Follow-up reached 3707.8 patient-years.

Results: Actuarial survival at $1,5,10,15,20$, and 25 years was $97 \% \pm 0.01 \%$, $90.4 \% \pm 0.017 \%, 85.3 \% \pm 0.023 \%, 82.3 \% \pm 0.025 \%, 71.7 \% \pm 0.036 \%$, and $70.2 \% \pm 0.038 \%$, respectively. At multivariate analysis, atrial fibrillation at follow-up was identified as an independent risk factor for late mortality, whereas left ventricular ejection fraction at 12 postoperative months proved to be a protective factor. Freedom from thromboembolism at 1, 5, 10, 15, 20, and 25 years was $98.1 \%$ $\pm 0.01 \%, 94.1 \% \pm 0.015 \%, 89.1 \% \pm 0.021 \%, 85.9 \% \pm 0.025 \%, 81.1 \% \pm 0.031 \%$, and $75.3 \% \pm 0.063 \%$, respectively. Atrial fibrillation and Carbomedics device were significantly associated with an increase in thromboembolic events. Freedom from reoperation at $1,5,10,15,20$, and 25 years was $99.2 \% \pm 0.005 \%, 95 \% \pm 0.014 \%$, $91.6 \% \pm 0.018 \%, 88.6 \% \pm 0.022 \%$, and $85.7 \% \pm 0.041 \%$. Type of prosthesis (tilting disc) was identified as a predictor of reoperation. At the end of the study, 208 patients were still alive: 94.7\% were in New York Heart Association class I or II. When receiving warfarin therapy, no patient undertaking pregnancy $(\mathrm{n}=35)$ experienced adverse cardiac or valve-related events. Fetal events were significantly less frequent with a daily warfarin dose less than $5 \mathrm{mg}$.

Conclusions: Mechanical devices provided excellent performance, safety, and durability. The prognostic role of left ventricular function and atrial fibrillation overwhelmed any differences that might exist between different prosthetic designs. Pregnancies entail virtually no maternal risk and predictable fetal complications.

$\mathrm{T}$ The optimal surgical strategy for rheumatic mitral valve disease is still highly debated. ${ }^{1-3}$ The peculiar management issues relating to the childbearing potential of young women, a highly represented patient subset, add to the intrinsic challenge of dealing with this topic. ${ }^{4}$

The primary purpose of this article was to provide long-term follow-up data of isolated mitral valve replacement with mechanical prostheses over a 27-year period in a young rheumatic population. Maternal and fetal outcomes of pregnancies were also investigated. The secondary aim was to evaluate the influence of the type of replacement device on outcomes. 


\section{Material and Methods \\ Patient Population}

Between January 1975 and December 2002, 1567 patients were referred to the Department of Cardiothoracic and Respiratory Sciences of the Second University of Naples for mitral rheumatic disease. Reparative procedures were performed in 905 patients (57.7\%). The study population included young female patients (defined as 15 to 40 years old) who underwent isolated mitral valve replacement with mechanical prosthesis $(n=267)$.

\section{Operative Technique, Type of Prosthesis, and Anticoagulation Management}

Prosthesis implantation was performed by using the same principles of technique throughout the study period. All the prostheses were implanted at the supra-annular level by using Tevdek 2-0 (Genzyme Surgical Products, Tucker, Ga) mattress sutures. Given the severe involvement of the subvalvular apparatus, chordal preservation in this subgroup was feasible in only 12 cases $(4.45 \%)$. Biological prostheses were not favored in this patient subset by policy. The choice of prosthetic model was made on the basis of availability, surgeon preference, or both. Seventy-three patients received a caged ball, 133 a tilting disc, and 61 a bileaflet prosthesis. Anticoagulation with warfarin was begun on the second postoperative day in all patients. The targeted international normalized ratio (INR) ranged from 3.0 to 4.0 for patients with caged ball or tilting disc prostheses and from 2.5 to 3.5 for those with bileaflet valves. Prophylaxis included aspirin $100 \mathrm{mg} / \mathrm{d}$ in $79.4 \%$ of the patients receiving a caged ball prosthesis. The adequacy of the anticoagulation level was followed up in our Anticoagulation Outpatient Clinic, and doses of warfarin were adjusted according to INR assessments performed at least monthly.

\section{Management of Pregnant Women}

Our anticoagulation protocol was based on sodium warfarin administration. Only 2 patients, after general practitioner counseling, preferred heparin treatment (unfractionated subcutaneous heparin). As previously described, ${ }^{4,5}$ cesarean delivery was scheduled before the end of the 37th gestational week. Warfarin therapy was discontinued only 2 days before delivery and was restarted 1 day after delivery: during that period, heparin was not administered, and INR was checked daily. Throughout pregnancy, INR was estimated weekly at our outpatient clinic and recorded along with prescribed warfarin doses. Echocardiographic follow-up was performed monthly, and ultrasound evaluations of the fetus were performed at the third, fifth, and eighth months. Neonates underwent clinical examination soon after birth and then at 4 and 12 months to ascertain or exclude the diagnosis of warfarin embryopathy.

\section{Follow-up and Statistical Analysis}

Data on patients undergoing valve replacement at the Department of Cardio-Thoracic and Respiratory Sciences were entered into a data chart archive. Data regarding hospitalization were obtained from hospital records. Patients were followed up at our outpatient clinic 15 days, 1 month, 12 months, and then yearly after surgery. On each visit, patients underwent physical examination, laboratory tests, and electrocardiogram. The first follow-up echocardiographic evaluation was performed at our institution 6 months after surgery. Questionnaires were sent to the general practitioners of all patients not seen at the outpatient clinic. Follow-up was completed with phone interviews to either the patients or relatives if data were missing. All the available follow-up data were entered into a computerized database. The guidelines of The American Association for Thoracic Surgery and The Society of Thoracic Surgeons were used for reporting mortality, morbidity, and valve-related complications. ${ }^{6}$ As to pregnancy outcomes, main end points were maternal cardiac events (cardiac decompensation, valve thrombosis, and thromboembolism) and the occurrence of spontaneous abortion, stillbirth, or embryopathy.

SPSS software (version 10.1; SPSS Inc, Chicago, Ill) was used for statistical analysis. Data were expressed as mean $\pm \mathrm{SD}$ or counts and percentages when appropriate. Differences in categorical variables were compared by means of the $\chi^{2}$ Pearson test or Fisher exact test. Continuous variables were analyzed with 2 -tailed Student $t$ tests. Nonparametric tests were used when necessary. With regard to survival, we considered the patient as a statistical unit, whereas in the analysis of valve-related events we followed the fate of the implanted mechanical prostheses: in case of reoperation with valve prosthesis replacement, the follow-up was truncated at the time of reoperation. Incidences of postoperative events are presented as absolute frequencies and linearized rates (percentage per patient-year) and were compared by using the likelihood ratio test. Actuarial survival, freedom from reoperation, and thromboembolism were calculated with the time-life table method. Comparisons between groups were performed with the nonparametric Wilcoxon-Gehan pairwise test. The Cox proportional hazards model (multivariate forward stepwise regression) was used to determine the relative risk of late death and valve-related complications (thromboembolism and reoperation) associated with perioperative variables. All variables tested at univariate analysis were also included in this analysis (Appendix 1). Predictive factors for poor pregnancy outcome were assessed in univariate and multivariate analyses of the following variables: patient age, prosthetic model, average INR, and average warfarin daily dose. Units of analysis were pregnancies rather than women because the focus was on the effect on the fetus of drug assumption. However, because pregnancies occurring in the same woman share some common risk factors, we analyzed differences between first and subsequent pregnancies, and eventually we adjusted for it in multivariate analysis. These analyses were performed by S-Plus software (S-PLUS 2000; MathSoft, Inc, Cambridge, Mass). The effect of drug assumption on pregnancy outcome after adjustment by order of pregnancy (first or subsequent) was evaluated by the exact logistic regression model with LogXact software to account for the small sample size (LogXact-Turbo; CYTEL Software Corporation, Cambridge, Mass).

\section{Results}

Baseline characteristics and operative variables are summarized in Table 1.

\section{Hospital (30-Day) Mortality}

Overall 30-day mortality was $1.12 \%$ (3 patients). Causes of death were cardiogenic shock in 2 cases and cardiac rupture in 1 . 
TABLE 1. Patient population data and follow-up time periods

\begin{tabular}{|c|c|c|c|c|}
\hline Variable & CB $(n=73)$ & $\mathrm{TD}(\mathrm{n}=133)$ & $B L(n=61)$ & Total $(n=267)$ \\
\hline Age (y) & $31.1 \pm 7.03$ & $30.8 \pm 6.25$ & $32.8 \pm 5.95$ & $31.4 \pm 6.4$ \\
\hline \multicolumn{5}{|l|}{ Valvular disease } \\
\hline Stenosis & $29(39.7)$ & $68(51.1)$ & $28(45.9)$ & $125(46.8 \%)$ \\
\hline Mixed & $44(60.3)$ & $65(48.9)$ & $33(54.1)$ & $142(53.2 \%)$ \\
\hline \multicolumn{5}{|l|}{ Preoperative NYHA class* } \\
\hline I-II & $60(82.2)$ & $43(32.3)$ & $42(68.9)$ & $145(54.3 \%)$ \\
\hline III-IV & $13(17.8)$ & $90(67.7)$ & $19(31.1)$ & $122(45.7 \%)$ \\
\hline Preoperative AF† & $43(58.9)$ & $78(58.6)$ & $23(37.7)$ & $138(51.7 \%)$ \\
\hline Previous open mitral commissurotomy $\ddagger$ & $1(1.4)$ & $11(8.3)$ & $1(1.6)$ & $13(4.9 \%)$ \\
\hline Emergency & $3(4.2)$ & $6(4.5)$ & $3(4.8)$ & $12(4.5)$ \\
\hline \multicolumn{5}{|l|}{ Operation era } \\
\hline $1975-1980$ & $29(39.7)$ & $18(13.5)$ & - & $47(17.6 \%)$ \\
\hline 1981-1985 & $36(49.3)$ & $55(41.4)$ & $1(1.6)$ & $92(34.5 \%)$ \\
\hline 1986-1990 & $6(8.2)$ & $54(40.6)$ & $6(9.8)$ & $66(24.7 \%)$ \\
\hline 1991-1995 & $1(1.4)$ & $6(4.5)$ & $24(39.3)$ & $31(11.6 \%)$ \\
\hline 1996-2002 & $1(1.4)$ & - & $30(49.2)$ & $31(11.6 \%)$ \\
\hline Mean follow-up, y (median) & $17.18 \pm 7.21(18.5)$ & $15.6 \pm 6.18(16.5)$ & $6.94 \pm 4.5(6.2)$ & $14.04 \pm 7.29(15.9)$ \\
\hline Cumulative patient-year & 1220.1 & 2063.8 & 423.9 & 3707.8 \\
\hline
\end{tabular}

Data are mean \pm SD unless otherwise noted. Categorical data are presented as: conts (percentages). $B L$, Bileaflet; $C B$, caged ball; $T D$, tilting disc; $N Y H A$, New York Heart Association; $A F$, atrial fibrillation. $* P<.001 ; \dagger P=.016 ; \ddagger P=.035$.

\section{Follow-up and Late Mortality}

No patient was lost to follow-up: $56.1 \%$ patients were seen every year, and in the other $38.3 \%$, yearly data from outpatient visits, general practitioner questionnaires, or phone interviews were available. For the remaining $5.6 \%$ of the population, the information was updated to February 2003, although data were not available for each year. The cumulative follow-up was 3707.8 patient-years, ranging from 0.1 to 27.1 years (mean, $4.04 \pm 7.29$ years; median, 15.9 years). Bileaflet devices had a significantly shorter observation period $(P<.001)$. There were $56(21.2 \%)$ late deaths. Table 2 summarizes causes of death. Long-term actuarial survival at $1,5,10,15,20$, and 25 years was $97 \% \pm 0.01 \%, 90.4 \%$ $\pm 0.017 \%, 85.3 \% \pm 0.023 \%, 82.3 \% \pm 0.025 \%, 71.7 \% \pm$ $0.036 \%$, and $70.2 \% \pm 0.038 \%$, respectively (Figure E1).
Valve-related and non-valve-related events are reported in Table 3. Table 4 shows the variables associated in univariate analysis with significantly higher mortality. At multivariate analysis, chronic atrial fibrillation was identified as an independent risk factor for late mortality; left ventricular ejection fraction at 12 postoperative months proved to be a protective factor (Table 5). When plotting long-term survival according to the type of replacement device implanted, no statistically significant difference emerged $(P=.34)$.

\section{Complications}

There was no primary mechanical dysfunction. Eighteen patients $(6.8 \%)$ experienced obstructive valve thrombosis. One died during echocardiography examination at the time of hospital readmission, 3 patients were treated with throm-

TABLE 2. Late mortality

\begin{tabular}{|c|c|c|c|c|c|c|}
\hline Variable & $1 y$ & $5 y$ & $10 y$ & $15 y$ & $20 y$ & $25 y$ \\
\hline $\begin{array}{l}\text { No. deaths } \\
\text { Actuarial survival (mean } \pm S D \text { ) }\end{array}$ & $\begin{array}{c}8 \\
97 \pm 0.01\end{array}$ & $\begin{array}{c}21 \\
90.4 \pm 0.017\end{array}$ & $\begin{array}{c}36 \\
85.3 \pm 0.023\end{array}$ & $\begin{array}{c}42 \\
82.3 \pm 0.025\end{array}$ & $\begin{array}{c}55 \\
71.7 \pm 0.036\end{array}$ & $\begin{array}{c}56 \\
70.2 \pm 0.038\end{array}$ \\
\hline Cause of death & \multicolumn{4}{|c|}{ n (\%) } & \multicolumn{2}{|c|}{ Cumulative $\%$ patient/year } \\
\hline Cardiac & \multicolumn{4}{|c|}{$48(85.7)$} & \multicolumn{2}{|c|}{1.3} \\
\hline Noncardiac & \multicolumn{4}{|c|}{$8(14.3)$} & \multicolumn{2}{|c|}{0.2} \\
\hline Valve related & \multicolumn{4}{|c|}{$25(44.6)$} & \multicolumn{2}{|c|}{0.67} \\
\hline Ascertained & \multicolumn{4}{|c|}{$12(21.4)$} & \multicolumn{2}{|c|}{0.32} \\
\hline Sudden unexplained & \multicolumn{4}{|c|}{$13(23.2)$} & \multicolumn{2}{|c|}{0.35} \\
\hline Non-valve related & \multicolumn{4}{|c|}{$31(55.4)$} & \multicolumn{2}{|c|}{0.33} \\
\hline Total & \multicolumn{4}{|c|}{$56 / 264(21.2)$} & \multicolumn{2}{|c|}{1.5} \\
\hline
\end{tabular}


TABLE 3. Follow-up events

\begin{tabular}{lcc}
\hline Variable & $\mathbf{n}(\%)$ & $\begin{array}{c}\text { Cumulative \%) } \\
\text { patient-years }\end{array}$ \\
\hline Thromboembolism* & $35(13.1)$ & 1.06 \\
Caged ball & $8(11.3)$ & 0.69 \\
Tilting disc & $16(12.1)$ & 0.92 \\
Bileaflet & $11(18)$ & 2.7 \\
Thrombosis $†$ & $18(6.8)$ & 0.51 \\
Caged ball & - & 0 \\
Tilting disc & $15(11.4)$ & 0.81 \\
Bileaflet & $3(4.9)$ & 0.66 \\
Nonstructural dysfunction $\ddagger$ & $18(6.8)$ & 0.52 \\
Caged ball & $3(4.2)$ & 0.25 \\
Tilting disc & $14(10.6)$ & 0.75 \\
Bileaflet & $1(1.6)$ & 0.24 \\
Bleeding & $3(1.1)$ & 0.08 \\
Caged ball & - & 0 \\
Tilting disc & $2(1.5)$ & 0.1 \\
Bileaflet & $1(1.6)$ & 0.22 \\
Endocarditis & $1(0.4)$ & 0.03 \\
Caged ball & - & 0 \\
Tilting disc & $1(0.8)$ & 0.054 \\
Bileaflet & - & 0 \\
Reoperation* & $28(10.6)$ & 0.8 \\
Caged ball & $1(1.4)$ & 0.08 \\
Tilting disc & $26(19.7)$ & 1.4 \\
Bileaflet & $1(1.6)$ & 0.22 \\
\hline P & & \\
\hline
\end{tabular}

$* P<.001 ; \nmid P=.006 ; \ddagger P=.039$. bolysis ( 2 deaths), and the remaining patients underwent reoperation ( 2 deaths). A total of 35 thromboembolic events occurred in this series: $21(60 \%)$ were major events that led to permanent functional impairment or death, and 14 (40\%) were minor (almost all transient or reversible ischemic attacks). Freedom from thromboembolism at 1, 5, 10, 15, 20 , and 25 years was $98.1 \% \pm 0.01 \%, 94.1 \% \pm 0.015 \%$, $89.1 \% \pm 0.021 \%, 85.9 \% \pm 0.025 \%, 81.1 \% \pm 0.031 \%$, and $75.3 \% \pm 0.063 \%$, respectively, with a linearized rate of $1.06 \%$ patients per year. When we reviewed the anticoagulant status of patients who experienced thromboembolic events, it seemed that $5.7 \%$ were inadequately anticoagulated. The rhythm at the time of the events was atrial fibrillation in $88.5 \%$ and normal sinus rhythm in $11.5 \%$ of cases. Stratifying freedom from thromboembolism according to replacement device, significantly worse outcomes were detected in patients receiving a bileaflet device (Figure E2).

Eight of 11 thromboembolic events in the bileaflet group were detected in patients who underwent mitral valve replacement with a Carbomedics device. Risk factor analysis revealed atrial fibrillation as the strongest predictor of thromboembolism; at the final step of the regression model, implying atrial fibrillation as a constant, the Carbomedics device emerged as a significant covariate in the equation (Table 5). Three patients, all in the caged ball group, experienced major nonfatal bleeding events (all gastrointestinal).

TABLE 4. Factors significantly associated with late death, thromboembolism, and reoperation in univariate analysis

\begin{tabular}{|c|c|c|c|c|c|c|}
\hline Variable modalities & Late mortality & $P$ value & Thromboembolism & $P$ value & Reoperation & $P$ value \\
\hline Valvular disease & & .039 & & .35 & & .39 \\
\hline Stenosis $(\mathrm{n}=124)$ & $20(16.1 \%)$ & & $18(14.5 \%)$ & & $12(9.7 \%)$ & \\
\hline Mixed $(n=140)$ & $36(25.7 \%)$ & & $17(12.1 \%)$ & & $16(11.4 \%)$ & \\
\hline Previous OMC & & .014 & & .02 & & .01 \\
\hline Yes $(n=13)$ & $1(7.7 \%)$ & & $1(7.7 \%)$ & & $0(0 \%)$ & \\
\hline No $(n=251)$ & $55(21.9 \%)$ & & $34(13.5 \%)$ & & $28(11.1 \%)$ & \\
\hline Operation era & & $<.01$ & & .181 & & .028 \\
\hline $1975-1980(n=45)$ & $14(31.1 \%)$ & & $5(11.1 \%)$ & & $3(6.7 \%)$ & \\
\hline $1981-1985(\mathrm{n}=92)$ & $29(31.5 \%)$ & & $11(12 \%)$ & & $16(17.4 \%)$ & \\
\hline $1986-1990(n=66)$ & $9(13.6 \%)$ & & $9(13.6 \%)$ & & $8(12.1 \%)$ & \\
\hline $1991-1995(n=30)$ & $3(10 \%)$ & & $8(26.7 \%)$ & & $0(0 \%)$ & \\
\hline $1996-2002(n=31)$ & $1(3.2 \%)$ & & $2(6.5 \%)$ & & $1(3.2 \%)$ & \\
\hline Prosthesis type & & $<.01$ & & .49 & & $<.01$ \\
\hline Caged ball $(\mathrm{n}=71)$ & $25(35.2 \%)$ & & $8(11.3 \%)$ & & $1(1.4 \%)$ & \\
\hline Tilting disc $(\mathrm{n}=132)$ & $27(20.5 \%)$ & & $16(12.1 \%)$ & & $26(19.7 \%)$ & \\
\hline Bileaflet $(\mathrm{n}=61)$ & $4(6.6 \%)$ & & $11(18 \%)$ & & $1(1.6 \%)$ & \\
\hline Postoperative $\mathrm{AF}^{*}$ & & $<.01$ & & .016 & & .20 \\
\hline Yes $(n=174)$ & $54(31 \%)$ & & $29(16.7 \%)$ & & $21(12.1 \%)$ & \\
\hline \multirow[t]{2}{*}{ No $(\mathrm{n}=90)$} & $2(2.2 \%)$ & & $6(6.7 \%)$ & & $7(7.8 \%)$ & \\
\hline & Yes & & Yes & & Yes & \\
\hline $\mathrm{EF}^{*} \dagger($ mean $\pm \mathrm{SD}):$ & $48.6 \pm 6$ & $<.01$ & $54 \pm 8$ & .54 & $53.6 \pm 9$ & .37 \\
\hline
\end{tabular}

Categorical data are presented as: conts (percentages). $A F$, Atrial fibrillation; $E F$, ejection fraction; $O M C$, open mitral commissurotomy. *Defined as chronic atrial fibrillation in the follow-up period; fintroduced in multivariate analysis as a continuous variable. 
TABLE 5. Multivariate analysis for late death, reoperation, and thromboembolic events

\begin{tabular}{lrrlc}
\hline Risk factor & $\boldsymbol{\beta}$ & HR & 95\% CI & P value \\
\hline Late death & & & & \\
$\quad$ EF at 12 months & -.08 & 0.89 & $0.88-0.92$ & $<.001$ \\
$\quad$ Postoperative AF & 1.87 & 6.50 & $1.52-27.87$ & $<.001$ \\
$\begin{array}{l}\text { Reoperation } \\
\quad \text { Type of prosthesis: }\end{array}$ & 2.8 & 16.63 & $2.25-122.8$ & .004 \\
$\quad$ ilting disc & & & & \\
$\begin{array}{l}\text { Thromboembolism } \\
\quad \text { Postoperative AF }\end{array}$ & 2.4 & 11.27 & $3.67-34.67$ & $<.001$ \\
$\quad \begin{array}{l}\text { Prosthetic model: } \\
\quad \text { Carbomedics }\end{array}$ & 1.6 & 4.82 & $1.45-15.99$ & .01 \\
\hline
\end{tabular}

$\overline{A F \text {, Atrial fibrillation; } E F \text {, ejection fraction; } H R \text {, hazard ratio; } C l \text {, confidence }}$ interval.

Nonstructural dysfunction (paravalvular leak in the absence of endocarditis and pannus formation) occurred in 18 (6.8\%) patients. Late prosthetic valve endocarditis developed in 1 patient $(0.4 \%)$, who successfully underwent reoperation. Twenty-eight patients $(10.6 \%)$ underwent reoperation for valve-related complications (13 nonstructural dysfunction, 14 valve thrombosis, and 1 endocarditis), with 2 deaths (in the thrombosis group). Freedom from reoperation at $1,5,10,15,20$, and 25 years was $99.2 \% \pm 0.005 \%$, $95 \% \pm 0.014 \%, 91.6 \% \pm 0.018 \%, 88.6 \% \pm 0.022 \%$, and $85.7 \% \pm 0.041 \%$ (Figure E3), with an incidence of $0.8 \%$ patients per year. The implantation of a tilting disc prosthesis was identified as determinant for reoperation.

\section{Functional Class and Echocardiographic Results}

At the end of follow-up, 208 patients (78.8\%) were still alive: $61.1 \%$ were in New York Heart Association class I, $33.6 \%$ were in class II, and $5.3 \%$ were in class III or IV. Electrocardiographic and echocardiographic examination results for patients who survived more than 20 years are reported in Table $6(n=52)$. No patient with a bileaflet device has yet reached such a long follow-up. Atrial fibrillation was seen in $46(88.5 \%)$ of 50 patients. The peak pressure gradients ranged between 6 and $27 \mathrm{~mm} \mathrm{Hg}$ (mean, $15.2 \mathrm{~mm} \mathrm{Hg}$ ). Atrial enlargement was found in all patients with a caged ball prosthesis. A stenotic condition with high gradients was seen in only 1 patient with a caged ball prosthesis; this patient is currently under evaluation for reoperation. The left ventricular configuration was normal in more than $80.8 \%$ (42 of 52) of patients. Five (9.6\%) of 52 patients had fractional shortening lower than $15 \%$, and 10 (19.2\%) of 52 patients had a left ventricular end diastolic diameter greater than $56 \mathrm{~mm}$.

\section{Pregnancies}

There were 48 pregnancies in 37 women. The 2 patients treated with heparin experienced valve thrombosis that ne-
TABLE 6. Echocardiographic and clinical examination at rest in patients with more than 20 years of follow-up

\begin{tabular}{lcc}
\hline Variable & $\begin{array}{c}\text { Caged ball } \\
(\mathbf{n}=\mathbf{2 7})\end{array}$ & $\begin{array}{c}\text { Tilting disc } \\
\text { (n= 25) }\end{array}$ \\
\hline Atrial enlargement $(>40 \mathrm{~mm})$ & $27(100 \%)$ & $21(84 \%)$ \\
LV dilatation $(>56 \mathrm{~mm})$ & $6(22.2 \%)$ & $4(16 \%)$ \\
Fractional shortening $<15 \%$ & $3(11.1 \%)$ & $2(8 \%)$ \\
Atrial fibrillation & $26(96.3 \%)$ & $20(80 \%)$ \\
NYHA class (III-IV) & $3(11.1 \%)$ & $2(8 \%)$
\end{tabular}

Categorical data are presented as: conts (percentages). $L V$, Left ventricle; NYHA, New York Heart Association.

cessitated surgical treatment, and they experienced perioperative abortion. With regard to the warfarin-treated subset, no patient experienced adverse cardiac or valve-related events during childbearing. There were 27 healthy babies, 16 spontaneous abortions, 2 stillbirths, and 1 embryopathy (small ventricular septal defect). Table 7 displays significant results of univariate and multivariate analysis for adverse fetal outcomes (cumulative mortality and morbidity).

\section{Discussion}

Over the last 3 decades, mitral surgery has evolved toward the tendency to preserve the native valve. In case of infeasible valve reconstruction, our practice has evolved from predominant implantation of bioprosthetic devices in the early 1970s to prevalent adoption of mechanical devices from the early 1980s on. Routine attempts to preserve the mitral chordae have been made since the early 1990s. The

TABLE 7. Univariate and multivariate analysis of pregnancy outcomes

\begin{tabular}{|c|c|c|c|}
\hline Variable & $\begin{array}{l}\text { No adverse } \\
\text { fetal events }\end{array}$ & $\begin{array}{l}\text { Adverse fetal } \\
\text { events }\end{array}$ & $P$ value \\
\hline Mean INR & $2.6 \pm 0.3$ & $2.4 \pm 0.1$ & $<.001$ \\
\hline Mean warfarin dose & $4.8 \pm 1.4$ & $7.3 \pm 1.6$ & $<.001$ \\
\hline Warfarin dose $(\mathrm{mg} / \mathrm{d})$ & & & $<.001$ \\
\hline$>5$ & $4(19 \%)$ & $17(85.2 \%)$ & \\
\hline$\leq 5$ & $23(81 \%)$ & $2(8 \%)$ & \\
\hline \multicolumn{4}{|l|}{ Order of pregnancy } \\
\hline First & $25(71.4 \%)$ & $10(28.6 \%)$ & .003 \\
\hline Subsequent & $2(18.2 \%)$ & $9(81.8 \%)$ & \\
\hline Exact logistic regression & & OR & \\
\hline model covariate* & $\boldsymbol{\beta}$ & (exact 95\% Cl) & $P$ value \\
\hline $\begin{array}{l}\text { Warfarin dose }>5 \text { vs } \\
\quad<5 \mathrm{mg}\end{array}$ & 3.7 & $41.7(5.8-298.4)$ & $<.001$ \\
\hline $\begin{array}{l}\text { Subsequent vs first } \\
\text { pregnancy }\end{array}$ & -.21 & $0.75(0.25-6.2)$ & .65 \\
\hline
\end{tabular}

Categorical data are presented as: conts (percentages). No significant difference was found for maternal age and prosthetic model. INR, International normalized ratio; $O R$, odds ratio; $C l$, confidence interval. $* r^{2}=0.687$. 
appropriateness of mitral valve repair for rheumatic disease is still controversial, ${ }^{2,3}$ and, in particular, severe mitral stenosis and mixed mitral disease yield the worst long-term results in terms of freedom from reoperation. ${ }^{7,8}$ Conversely, the quest for the ideal replacement device for young women of childbearing age remains open.

The young rheumatic population, free from significant comorbidities, provides a good model for purely assessing valve performance over the long term. ${ }^{9}$ The most important findings of this study were as follows: (1) more than $56 \%$ of the fatal events were due to worsening cardiac function; (2) in long-term follow-up, mechanical prostheses imply acceptable complication rates; and (3) warfarin therapy during pregnancy allows virtually no maternal events and predictable fetal complications.

The evidence that the determinants of long-term survival are chronic atrial fibrillation and early postoperative left ventricular performance confirms the already stressed need for early surgical treatment ${ }^{10,11}$ and favors the preservation of the subvalvular apparatus and concomitant operation for atrial fibrillation. Freedom from thromboembolism in this study seems superior to that reported elsewhere. ${ }^{12-14}$ Two major reasons for this low complication rate may be the mean age of the patients (younger than that reported in most series) and the close anticoagulation follow-up, coupled with the compliance of the patient population. The literature has not yet provided any appropriate evidence to determine whether the advancements in prosthesis design have led to a reduction in thromboembolic and hemorrhagic risk. Murday and colleagues ${ }^{11}$ have performed the only prospective randomized trial comparing the St Jude Medical and the Starr-Edwards prostheses in the English literature, and they reported similar thromboembolism and antithrombotic hemorrhage rates with the 2 prostheses. Notably, these results were achieved with a target INR of 3.0 to 4.0 with both valve types. Jamieson and coworkers ${ }^{13}$ reported a linearized rate of thromboembolism as high as $5 \%$ per patient-year with bileaflet devices under lower INR ranges, and similar outcomes were reported by others. ${ }^{15,16}$ In this series, the higher rates of thromboembolism in the bileaflet group may be partly explained by the lower-intensity anticoagulation protocol and by the higher incidence of sudden deaths in the tilting disc and caged ball groups; this may have masked the real incidence in these patient subsets. It is noteworthy that in multivariate analysis, the bileaflet model was not an independent predictor of thromboembolism. Again, postoperative atrial fibrillation was a strong risk factor. The finding that most of the events in the bileaflet group occurred in patients with a Carbomedics device is consistent with published data. Nevertheless, comparative studies with other third-generation devices failed to confirm such evidence. ${ }^{10-14}$
Overall freedom from reoperation proved satisfying and far better than that reported with bioprostheses or mitral repair. ${ }^{12,17,18}$ Tilting disc devices showed the highest rate of nonstructural dysfunction (namely, pannus formation), in accordance with larger series. ${ }^{14}$

Anticoagulant management of pregnant women with mechanical heart valves is still troublesome. No controlled clinical trial has yet demonstrated which is the safest regimen for the mother and the baby. ${ }^{19}$ The special management protocol of patients with prosthetic heart valves undergoing pregnancy at our institution has already been published ${ }^{4,5}$ and also incorporated in a recent clinician update. ${ }^{20} \mathrm{Me}-$ chanical mitral replacement allows favorable maternal and fetal outcomes, especially in women affected by mitral stenosis. ${ }^{21}$ Our data showed that in this setting, the occurrence of pregnancy does not increase the risk of valverelated complications; fetal events remain within an acceptable range unless the mean warfarin daily dose required to maintain a therapeutic INR exceeds $5 \mathrm{mg}$. The mean annual rate of spontaneous abortions observed in this series approached $12.9 \%$ and it is worth reporting that, as issued by the Ministry of Health, the mean annual rate in the Italian population is $4.4 \%$ (ranging from $0.8 \%$ o to $8.5 \%$ occording to maternal age). Comparisons with pregnancy outcomes and maternal events both in women with untreated rheumatic disease and in those with biologic devices or percutaneous mitral plasty may provide more insights on these results. ${ }^{21,22}$ It is worthy of mention that a previous study from our group could not find any correlation between prosthetic type and pregnancy outcome. ${ }^{5}$

\section{Limitations of the Study}

Being retrospective, this study could have implied some incompleteness of information. This is particularly true for the incidence of thromboembolism, which might have been the most frequent cause of sudden unexplained deaths in the caged ball and tilting disc prosthesis groups, and, therefore, the rate of such complications in survivors would be lower. Similarly, because of the retrospective design, no analysis was performed of the adequacy of anticoagulation in the overall population and, in particular, in the subgroups of patients experiencing thrombosis, thromboembolism, or bleeding events. The long-term retrospective design, even on a specific patient population, might have affected the comparison between different devices. Indeed, different preoperative conditions, management strategies, and follow-up times somehow weakened the study results.

\section{Conclusions}

Mechanical prostheses in young women provide gratifying long-term survival and freedom from valve-related morbidity, though inherent patient and study characteristics have to be considered when evaluating these outcomes. No type of 
prosthesis has so far shown a significant superiority in terms of survival, although a better trend was observed with bileaflet models. Unless a longer follow-up period $(>15$ years) and a larger series of bileaflet devices will allow confirmation of this trend, the preference of 1 type of prosthesis over another in this subset of patients will not be supported by clinical evidence of greater appropriateness. The prognostic role of left ventricular function and atrial fibrillation overwhelmed any differences between prosthetic designs and with regard to thromboembolism. Pregnancies can be undergone with very low maternal risk.

\section{References}

1. Cotrufo M, Vitale N, Cafarella G, De Feo M. Discussion article: valve repair in rheumatic mitral valve disease: is it always worth trying? J Heart Valve Dis. 1997;6:370-2.

2. Duran CM, Gometza B, De Vol EB. Valve repair in rheumatic mitral disease. Circulation. 1991;84:III125-32.

3. Grossi EA, Galloway AC, Miller JS, Ribakove GH, Culliford AT, Esposito R, et al. Valve repair versus replacement for mitral valve insufficiency: when is a mechanical valve still indicated? J Thorac Cardiovasc Surg. 1998;115:389-96.

4. Vitale N, De Feo M, De Santo LS, Pollice A, Tedesco N, Cotrufo M. Dose-dependent fetal complications of warfarin in pregnant women with mechanical heart valves. J Am Coll Cardiol. 1999;33:1637-41.

5. Cotrufo M, De Feo M, De Santo LS, Romano G, Della Corte A, Renzulli A, et al. Risk of warfarin during pregnancy with mechanical valve prostheses. Obstet Gynecol. 2002;99:35-40.

6. Edmunds LH Jr, Clark RE, Cohn LH, Grunkemeier GL, Miller DC, Weisel RD. Guidelines for reporting morbidity and mortality after cardiac valvular operation. Ann Thorac Surg. 1996;62:932-5.

7. Fernandez J, Joyce DH, Hirschfeld K, Chen C, Laub GW, Adkins MS, et al. Factors affecting mitral valve reoperation in 317 survivors after mitral valve reconstruction. Ann Thorac Surg. 1992;54:440-7.

8. Glower DD, Landolfo KP, Davis RD, Cen YY, Harrison JK, Bashore TM, et al. Comparison of open mitral commissurotomy with mitral valve replacement with or without chordal preservation in patients with mitral stenosis. Circulation. 1998;98:II120-3.

9. Grunkemeier GL, Wu Y. "Our complication rates are lower than theirs": statistical critique of heart valve comparisons. J Thorac Cardiovasc Surg. 2003;125:290-300.

10. Kontozis L, Skudicky D, Hopley MJ, Sareli P. Long-term follow-up of St. Jude Medical prosthesis in a young rheumatic population using low-level anticoagulation: an analysis of the temporal distribution of causes of death. Am J Cardiol. 1998;81:736-9.

11. Murday AJ, Hochstitzky A, Mansfield J, Miles J, Taylor B, Whitley E, et al. A prospective controlled trial of St. Jude versus Starr-Edwards aortic and mitral prostheses. Ann Thorac Surg. 2003;76:66-73.

12. Butchart EG. Prosthesis-specific and patient specific anticoagulation. In: Butchart EG, Bodnar E, editors. Current issues in heart valve disease, thrombosis, embolism and bleeding. London: IRC; 1992. p. 293-317.
13. Jamieson WR, Miyagishima RT, Grunkemeier GL, Germann E, Henderson C, Fradet GJ, et al. Bileaflet mechanical prostheses performance in mitral position. Eur J Cardiothorac Surg. 1999;15:786-94.

14. Akins CW. Mechanical cardiac valvular prostheses. Ann Thorac Surg. 1991;52:161-72.

15. Gödje OL, Fischlein T, Adelhard K, Nollert G, Klinner W, Reichart B. Thirty-year results of Starr-Edwards prostheses in the aortic and mitral position. Ann Thorac Surg. 1997;63:613-9.

16. Ibrahim M, O'Kank H, Cleland J, Gladstone D, Sarsam M, Patterson C. The St. Jude Medical prosthesis. A thirteen-year experience. J Thorac Cardiovasc Surg. 1994;108:221-30.

17. Kirali K, Guler M, Tuncer A, Daglar B, Ipek G, Isik O, et al. Fifteen-year clinical experience with the Biocor porcine bioprostheses in the mitral position. Ann Thorac Surg. 2001;71:811-5.

18. Santini F, Luciani GB, Restivo S, Casali G, Pessotto R, Bertolini P, et al. Over twenty-year follow-up of the standard Hancock porcine bioprosthesis implanted in the mitral position. Ann Thorac Surg. 2001; 71:S232-5.

19. Leyh RG, Fischer S, Ruhparwar A, Haverich A. Anticoagulant therapy in pregnant women with mechanical heart valves. Arch Gynecol Obstet. 2003;268:1-4.

20. Hung L, Rahimtoola SH. Prosthetic heart valves and pregnancy. Circulation. 2003;107:1240-6.

21. Sawhney H, Aggarwal N, Suri V, Vasishta K, Sharma Y, Grover A. Maternal and perinatal outcome in rheumatic heart disease. Int $J$ Gynaecol Obstet. 2003;80:9-14.

22. Hameed A, Karaalp IS, Tummala PP, Wani OR, Canetti M, Akhter MW. The effect of valvular heart disease on maternal and fetal outcome of pregnancy. J Am Coll Cardiol. 2001;37:893-9.

\section{Appendix 1: Variables Tested at Univariate Analysis and Included in the Multivariate Models Predicting Late Death, Reoperation, and Thromboembolic Events}

- Age

- Mitral valve disease (stenosis/mixed)

- Preoperative New York Heart Association class (I-II/III-IV)

- Previous open mitral commissurotomy (yes/no)

- Emergency operation (yes/no)

- Operation era (1975-1980/1981-1985/1986-1990/19911995/1996-2002)

- Prosthesis type (caged ball/tilting disc/bileaflet)

- Prosthetic model: Starr-Edwards (yes/no); Sorin standard (yes/no); Sorin Carbocast (yes/no); Björk-Shiley (yes/no); other tilting disc models (models implanted in $<5 \%$ of patients each), including Sorin All Carbon, Lillehei-Kaster, and Medtronic-Hall (yes/no); Sorin Bicarbon (yes/no); Carbomedics (yes/no); or other bileaflet models (models implanted in $<5 \%$ of patients each), including St Jude Medical, Edwards Tekna, and Edwards Mira (yes/no)

- Postoperative atrial fibrillation (yes/no)

- Ejection fraction

. 


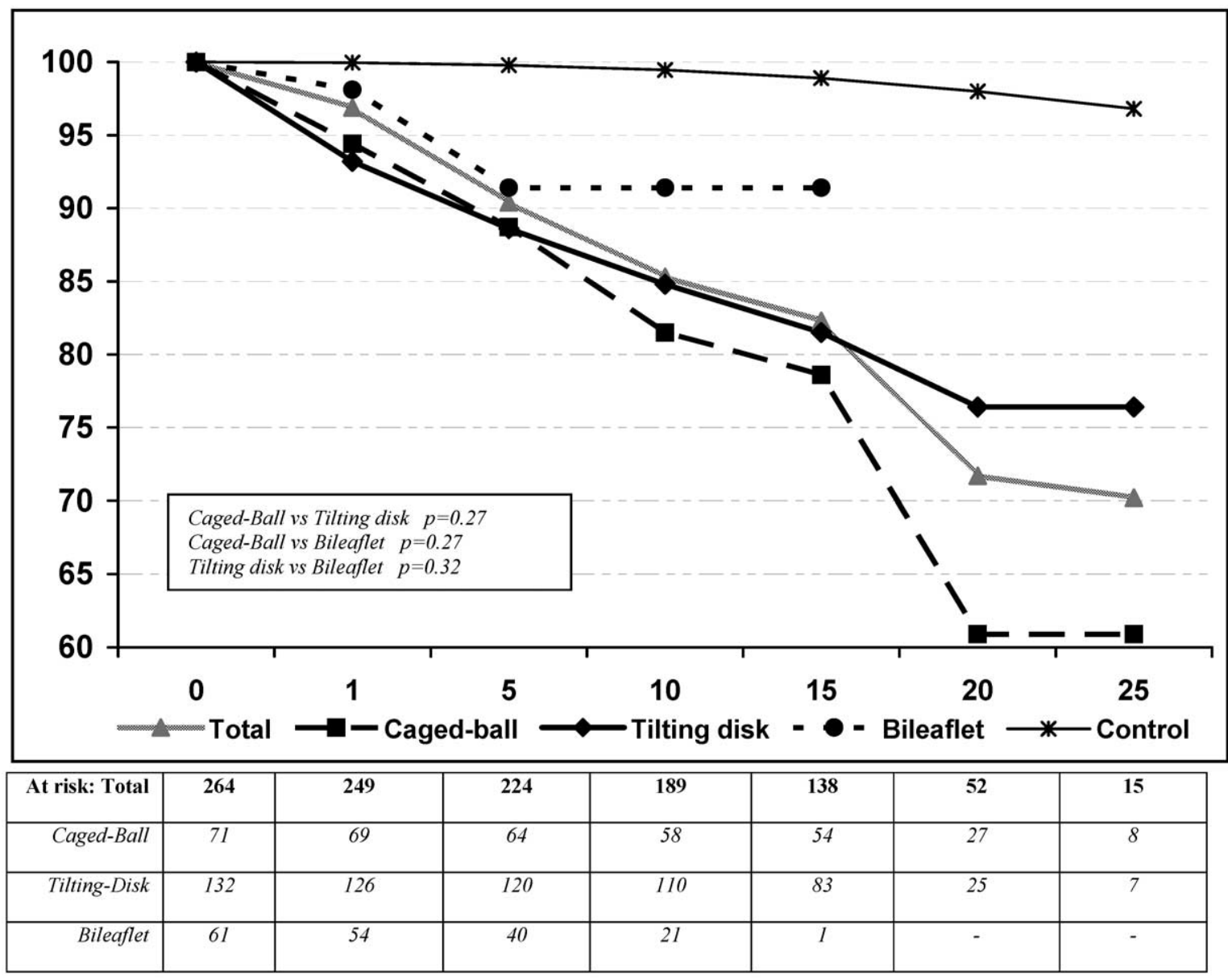

Figure E1. Actuarial survival curves of 264 isolated mitral replacement patients. The control curve shows the expected survival for an age- and sex-matched cohort from the general Italian population (data are available online at http://demo.istat.it). 


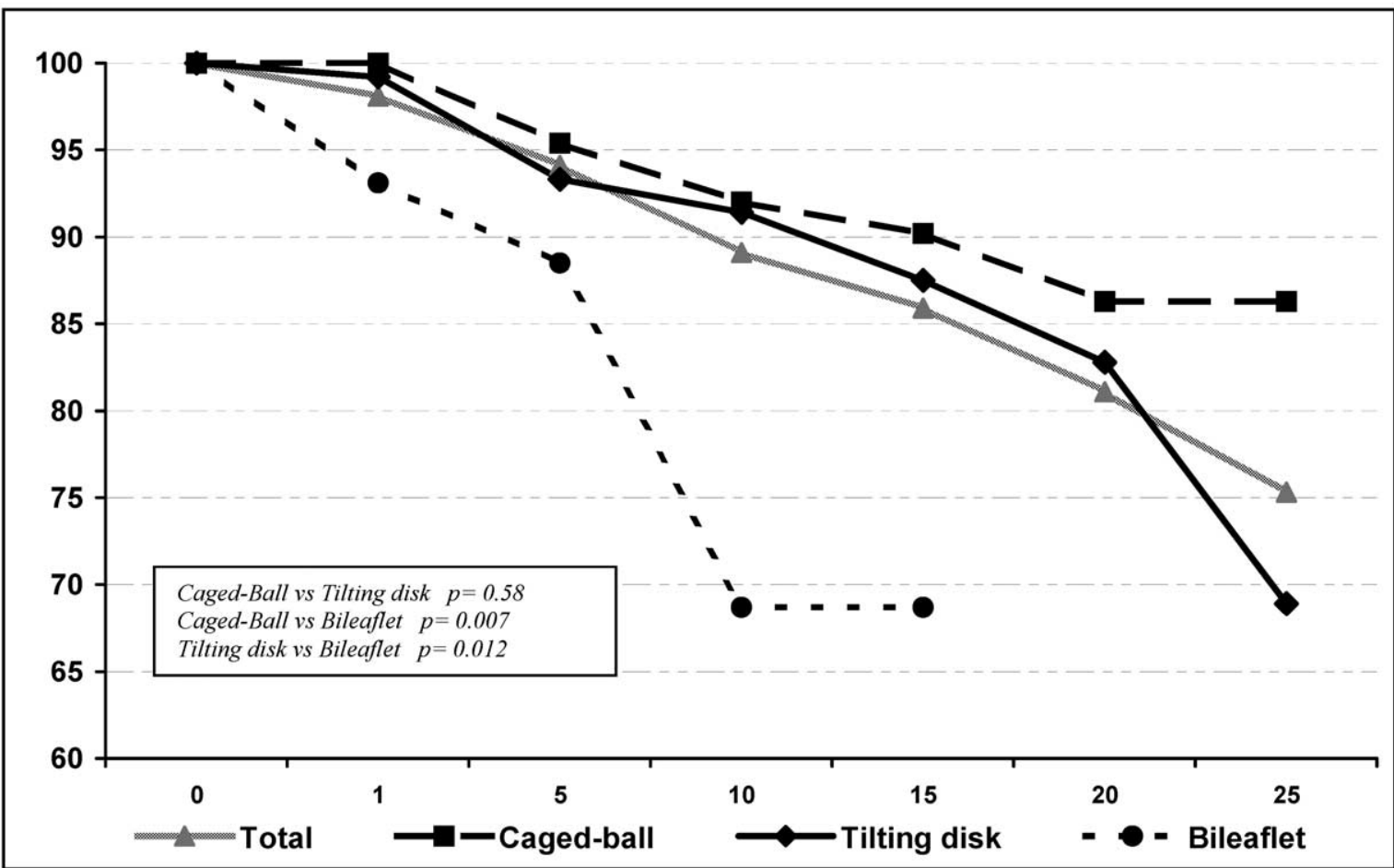

\begin{tabular}{|r|c|c|c|c|c|c|c|}
\hline At risk: Total & $\mathbf{2 6 4}$ & $\mathbf{2 4 2}$ & $\mathbf{2 0 4}$ & $\mathbf{1 6 0}$ & $\mathbf{1 1 5}$ & $\mathbf{4 2}$ & $\mathbf{1 2}$ \\
\hline Caged-Ball & 71 & 69 & 62 & 55 & 50 & 23 & 7 \\
\hline Tilting-Disk & 132 & 123 & 106 & 90 & 64 & 19 & 5 \\
\hline Bileaflet & 61 & 50 & 36 & 15 & 1 & - & - \\
\hline
\end{tabular}

Figure E2. Freedom from thromboembolism. 


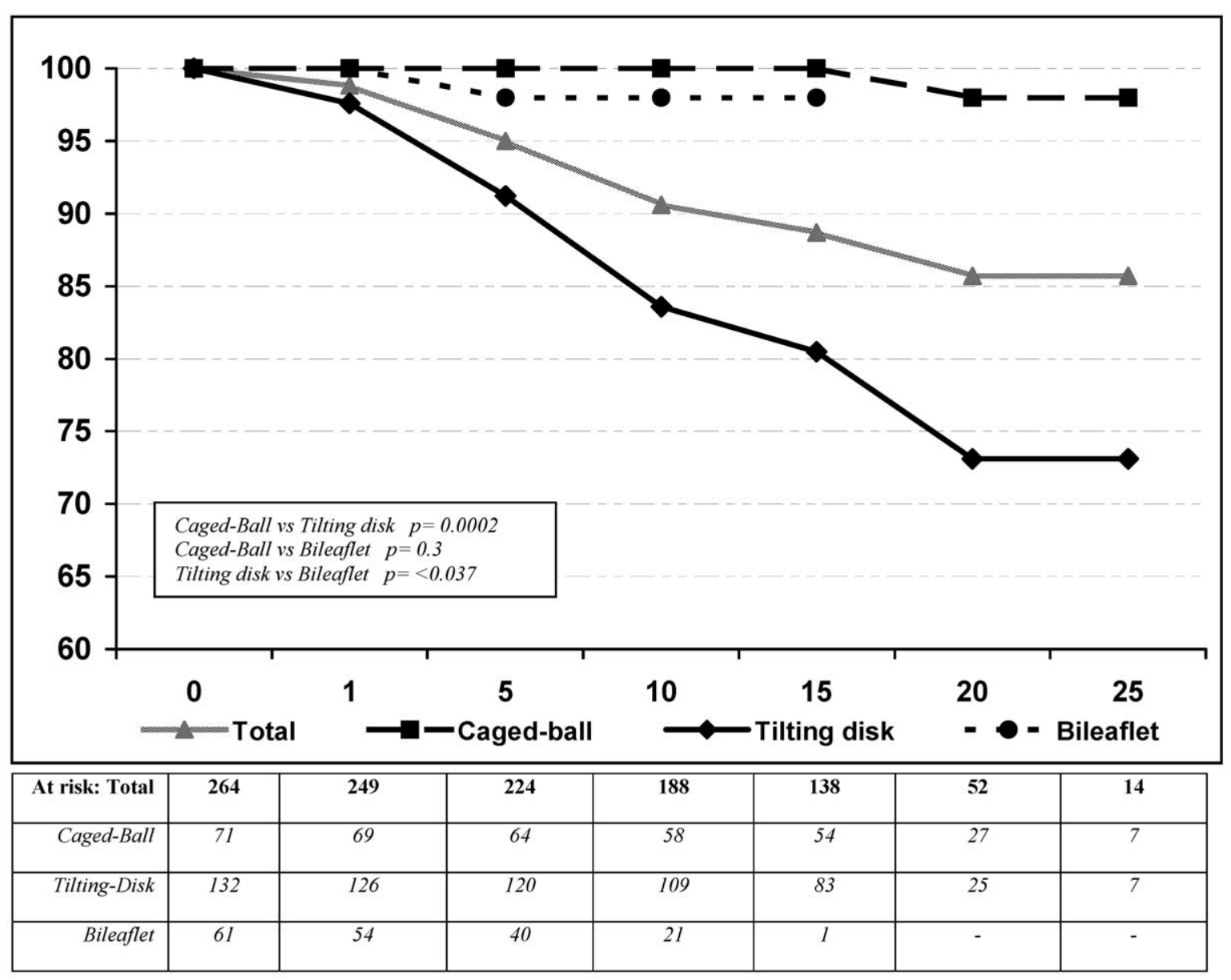

Figure E3. Freedom from reoperation. 